\title{
Purification of Raw Sugar Beet Juice by Electrocoagulation
}

\section{Habibeh Azizi ${ }^{1}$, Vahid Hakimzadeh ${ }^{1}$, Hossein Alizadeh Golestani ${ }^{2}$}

\author{
1 - Department of food science and technology, Quchan Branch, Islamic Azad \\ University, Quchan, Iran \\ 2 - Department of Chemical Engineering, Quchan Branch, Islamic Azad University, \\ Quchan, Iran
}

Keywords:

Sugar Bee

Electrocoagulation

Color

Purity

Turbidity

Article history:

Received

02.09.2016

Received in revised

form 14.11.2016

Accepted

27.12.2016

\section{Corresponding author:}

Vahid Hakimzadeh

E-mail:

v.hakimzadeh@

yahoo.com

DOI:

$10.24263 / 2304-$

974X-2016-5-4-6

\section{Abstract}

Introduction. This research was carried out to study of electrocoagulation process as a new technique for removal of impurities and non-sucrose compounds from raw sugar beet juice.

Materials and methods. This study was performed in a batch chemical reactor equipped with a 5-liters tank containing 3 aluminium anode and 3 Iron cathode electrodes connected in parallel. Effects of voltage at 5, 10 and 15 volts; processing time at 15,30 and 45 minute intervals; and $\mathrm{pH}$ value at $6,7 \& 8$ levels on the purity, turbidity and colour of the sugar beet juice were investigated by the Box-Behnken response surface methodology statistical design on Minitab 17 statistical software.

Results and Discussion. The results indicated that during the EC process, turbidity was reduced as the voltage increased. As the voltage rises, the solubility of the anodal electrodes also increases resulting in removal of a larger quantity of pollutants. Therefore, reduction in turbidity following the rise in voltage can be attributed to the increase in flake production, while changes in $\mathrm{pH}$ value had no significant effect on turbidity. Although the increase in voltage did not significantly effect the intensification of the colour, however it can be attributed to the increase in bubbles and the subsequent increase in enzymatic activity during floatation. It seems that the increase in enzymatic activity intensifies the melanin colour with the passage of time due to the openness of the reactor cell during flotation and aeration. Increase in the $\mathrm{pH}$ value, however, only slightly intensified the colour. The results indicated that the increase in voltage resulted in increase in the level of purity. The solubility of the anodal electrodes increases as the voltage rises and subsequently a higher quantity of impurities and polutants are removed by aluminium hydroxides produced. Increase in voltage also leads to production of greater quantity of bubbles which increase contact between aluminium hydroxides with the pollutants and impurities and facilitates the floatation of more of the produced sludge and thus removal of a greater quantity of the impurities. Increase in process time also resulted in an increase in the level of purity as an increase in reaction time results in more floating sludge is produced on the fluid surface. Increase in the $\mathrm{pH}$ value had no significant effect on the level of purity.

Conclusion. The results generally indicated that electrocoagulation process has positively affected on the turbidity reduction and increase the purity of the raw sugar beet juice during the process of purification though colour intensity was not so significantly influenced. 


\section{Introduction}

Purification, removal of impurities, i.e. the non-sucrose compounds from sucrose, is one of the critical challenges facing the sugar industry. Raw sugar beet juice contains 50 non-sucrose and impurities such as reducing sugars, organic and non-organic acids, amino acids, proteins, starch, wax, resin, minerals such as potassium, magnesium, calcium, and silicon, colour and floating substances [7]. Obtaining a raw sugar beet juice with the highest degree of purity and least colour is the main objective in the purification stages. Purification by the conventional method (Liming - carbonization) requires a high degree of precision in the addition of lime and carbon dioxide as lack of precise control in the addition of these compounds can result in only partial separation of the impurities from the juice and the fragmentation of the colour compounds adsorbed from calcium carbonate crystals [8]. Traditional purification method also produces a large quantity of pulp due to high consumption of lime resulting in environmental problems. The most important disadvantage of this method is its high energy consumption [16]. Therefore, considering the abovementioned points, use of modern technologies such as the membrane process, electrocoagulation etc. in the sugar industry seems essential.

Electrocoagulation is a process in which suspended particles, emulsion or soluble pollutants are destabilized in an aquatic environment by an electric current. This process is beneficial in a wide range of water and sewage purification systems, and removal of mineral, pollutants and pathogens [5]. This process begins with the oxidation of anodes and the production of $\mathrm{Al}^{+3}$ and $\mathrm{Fe}^{+2}$ ions and continues with the combination of the metallic ions with hydroxyl ions resultant from water electrolysis in the proximity of the cathode and the production of metallic hydroxides which destabilize the pollutants and creates suspended particles or flakes. These flakes can float on the surface of the fluid aided by the hydrogen bubbles produced in the cathode due to the difference in density or be removed through precipitation [3]. In general, the impurities removal mechanism in the electrocoagulation process includes coagulation, adsorption, precipitation, and floatation which are performed in accordance to the reactions below in the electrodes thus follows:

Anode reaction: $\mathrm{Al} \rightarrow \mathrm{Al}_{3}+3 e^{-}$

Cathode reaction: $3 \mathrm{H}_{2} \mathrm{O}+3 e^{-} \rightarrow \frac{3}{2} \mathrm{H}_{2}+3 \mathrm{OH}^{-}$

Production of Aluminium Flakes: $\mathrm{Al}^{3}+3 \mathrm{OH} \rightarrow \mathrm{Al}(\mathrm{OH})^{3}$

The $\mathrm{Al}^{3+}$ and $\mathrm{OH}^{-}$ions produced during above reactions are formed into monomers such as $\mathrm{Al}(\mathrm{OH})^{2+}, \mathrm{Al}(\mathrm{OH})_{2}^{+2}, \mathrm{Al}_{2}(\mathrm{OH})_{2}^{4+}$ and, $\mathrm{Al}(\mathrm{OH})_{4}^{-}$and or polymers such as $\mathrm{Al}_{6}(\mathrm{OH})_{15}^{3+}, \mathrm{Al}_{7}(\mathrm{OH})_{17}^{4+}, \mathrm{Al}_{8}(\mathrm{OH})_{20}^{4+}, \mathrm{Al}_{13} \mathrm{O}_{4}(\mathrm{OH})_{34}^{7+}$, and $\mathrm{Al}_{13}(\mathrm{OH})_{34}^{5+} \quad$ which $\quad$ are eventually changed into $\mathrm{Al}(\mathrm{OH})_{3}$ and become precipitated [9]. Insolubility of iron and aluminium hydroxides in water, availability and the low cost of these metals in comparison to metals with similar characteristics has resulted in their more widespread use in the process of electrocoagulation [10 \& 11]. Other advantages of this method also include: use of simple equipment, low initial investment and operation costs, unnecessity of chemical substances, low sludge production, production of larger, more stable and acid resistant flakes, faster filtration, elimination of small colloidal particles, and low repair and maintenance care [4]. The research by Shivayogimath and his collabrator, where they 
exploited electrocoagulation in the purification of the sugar industry wastewater, is among many examples of the application of this method. Their results indicated that the electrocoagulation process incorporating iron electrodes can be used as an affordable substitute for the traditional methods of purifying sugar industry wastewater [12]. Xu et al., (2002) also applied electrocoagulation in order to retrieve useful compounds from the wastewater produced by egg processing plants. Their results indicated that the use of this process in the egg processing industry can be very successful and lead to the recovery of fractions such as protein and highly digestible fat. Bazrafshan et al, (2013) used electrocoagulation in order to purify dairy wastewater and found that this is a suitable method for the removal of $\mathrm{BOD}_{5}, \mathrm{COD}$ and other pollutants.

With regard to the high potential of EC process in removing impurities, the purification of raw sugar beet juice was invetigated in this study through applying aluminium anode and iron cathode electrodes under the influence of parameters such as voltage, $\mathrm{pH}$ value, and process time in a batch chemical reactor.

\section{Materials and methods}

\section{Material}

The raw sugar beet juice was prepared from Chenaran sugar plant. Also, all the chemical material, component and reagent for determination of Turbidity, color and purity was purchased from Merck company.

\section{Methods}

\section{EC process}

This study was carried out in experimental form on a laboratory scale in a batch pilot. Properties of the raw sugar beet juice are given in Table 1. As shown in Figure 1, the electrocoagulation system consists of a 5 liter tank in which 3 alluminium electrodes as anode and 3 iron electrodes as cathode have been placed alternatively at a distance of $0.015 \mathrm{~m}$ from each other with a lateral surface area of $0.01875 \mathrm{~m}^{2}$ for each electrode connected to an electrical power supply in a unipolar form. The tests were performed at three voltage levels $(5,10$ and 15 volts), three $\mathrm{pH}$ levels $(6,7$ and 8$)$ and three time intervals $(15,30,45$ minutes). Firstly, $\mathrm{pH}$ of juice was adjusted with $0.1 \mathrm{M} \mathrm{NaOH}$, then five liters of raw sugar beet juice was poured into the electrocoagulation cell at each stage and the effects of the abovementioned parameters evaluated. At the end of the process, samples were taken from the mid - cell area and turbidity, colour, and purity of the raw sugar beet juice was tested after the precipitation of coagulums and filteration. 
Initial Properties of Raw Sugar Beet Juice

Table 1

\begin{tabular}{|c|c|c|}
\hline Variable & Unit & Value \\
\hline Turbidity & NTU & 166 \\
\hline PH & - & 6 \\
\hline Colour & ICUMSA & 10520 \\
\hline Pol & $\%$ & 13.2 \\
\hline Brix & $\%$ & 14.9 \\
\hline Degree of Purity & $\%$ & 88.6 \\
\hline
\end{tabular}

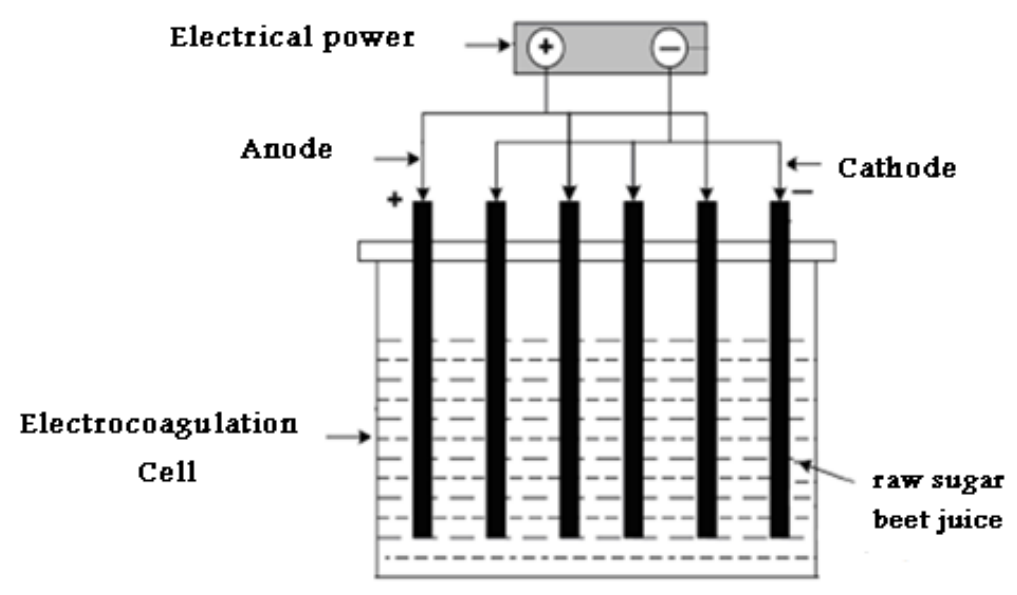

Figure 1. Electrocoagulation pilot schematic

\section{Measuring the colour}

The colour was measured following the absorption value reading taken at a wavelength of 420nm by the spectrophotometer model UNICO 2100 and evaluated according to the ICUMSA Standard using equation 1 below [15].

$$
\operatorname{Color}(I C U M S A)=10^{5} \times \frac{A}{L \times R D S \times \rho}
$$

where:

$A=$ Light absorption, $L=$ Cell Length, $\operatorname{RDS}=$ Refractometric Dry Solid and $\rho=$ Density 


\section{Turbidity}

Turbidity of the raw sugar beet juice was directly measured using the turbidimeter (Aqualytic ${ }^{\mathrm{TM}}$ AL450T-IR model) according to the NTU unit [14].

\section{Purity}

Purity was determined using equation 2 following the evaluation of Pol (percentage of sucrose) by NIR W2 Saccharometer and the percentage of solid matter by NAR-1T Refractometer [13].

$$
Q=\frac{\text { pot }}{\text { Brix }} \times 100
$$

\section{Experimental design}

Effects of independent variables: voltage, processing time, and $\mathrm{pH}$ value on the purity, turbidity and the colour of the raw sugar beet juice were examined in this study by the BoxBehnken response surface methodology statistical design subject the full quadratic model (equation 3) on Minitab 17 statistical software. where:

$$
f=b_{0}+b_{1} V+b_{2} V^{2}+b_{3} T+b_{4} T^{2}+b_{5} P+b_{6} P^{2}+b_{7} V T+b_{8} V P+b_{9} P T
$$

$\mathrm{V}=$ Voltage, $\mathrm{T}=$ Time and $\mathrm{P}=\mathrm{pH}$

Run numbers, experimental treatments and replicate runs designed by RSM is summarized in Table 2.

Experimental runs, independent variable levels and replicate runs in RSM

Table 2 (box-bhenken)

\begin{tabular}{|c|c|c|c|c|c|c|c|c|c|c|c|c|c|c|c|}
\hline Run Number & $\mathbf{1}$ & $\mathbf{2}$ & $\mathbf{3}$ & $\mathbf{4}$ & $\mathbf{5}$ & $\mathbf{6}$ & $\mathbf{7}$ & $\mathbf{8}$ & $\mathbf{9}$ & $\mathbf{1 0}$ & $\mathbf{1 1}$ & $\mathbf{1 2}$ & $\mathbf{1 3}$ & $\mathbf{1 4}$ & $\mathbf{1 5}$ \\
\hline Voltage (volt) & 5 & 15 & 15 & 15 & 5 & 15 & 5 & 15 & 10 & 10 & 10 & 10 & 10 & 10 & 10 \\
\hline Time (min) & 15 & 15 & 45 & 45 & 30 & 30 & 30 & 30 & 15 & 45 & 15 & 45 & 30 & 30 & 30 \\
\hline pH & 7 & 7 & 7 & 7 & 6 & 6 & 8 & 8 & 6 & 6 & 8 & 8 & 7 & 7 & 7 \\
\hline
\end{tabular}

\section{Results and discussion}

\section{Investigation of the effect of independent variables on raw sugar beet juice turbidity changes}

Turbidity is one of the most important factors that occurs in purification of the raw sugar beet juice. Turbidity can result from residual mud on the sugar beet, organic compounds, insoluable cellular compounds, beet plant fragments etc. As shown in Figure.2, the results indicated that during the EC process, turbidity was reduced as the voltage increased. As the voltage rises, the solubility of the anodal electrodes also increases resulting in removal of a larger quantity of pollutants. Therefore, reduction in turbidity following the rise in voltage can be attributed to the increase in flake production. In electrocoagulation procrss for the removal of seasonal turbidity from drinking water was found that the removal rate of turbidity significantly increased as the voltage increased. 
Increase in EC process time also led to an increase in coagulation and a higher rate of impurity removal. Efficacy of impurity removal is directly dependent upon the concentration of the ions produced on the electrodes, and as the concentration of the metal ions and hydroxide coagulums increases along with time increase, their rate of such removal also rises [1].
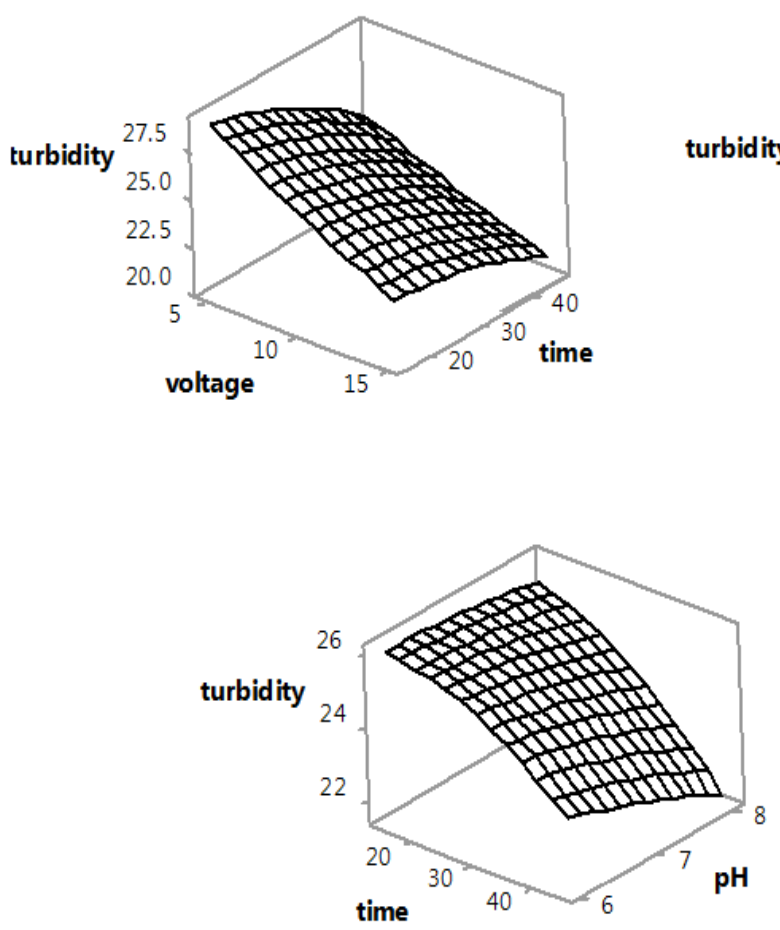

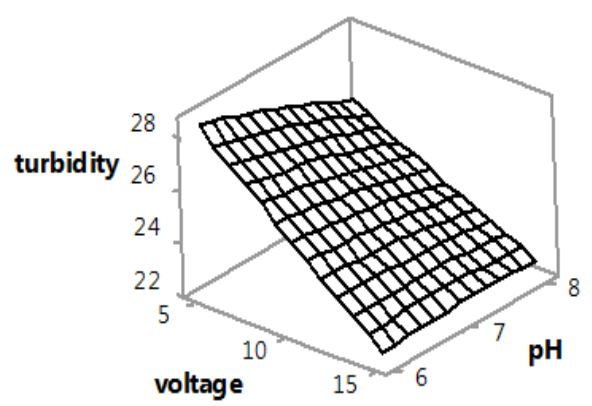

\begin{tabular}{|lr|}
\hline \multicolumn{2}{|l|}{ Hold Values } \\
voltage & 10 \\
time & 30 \\
$\mathrm{pH}$ & 7 \\
\hline
\end{tabular}

Figure 2. Effects of voltage, time and pH on variability of juice turbidity

Shivayogimath et al., (2012) found during the investigation of purification of the sugar industry sewage by electrocoagulation that the rate of removal of Turbidity increases with time and declared that the maximum amount of turbidity $(92.4 \%)$ is achieved after four hours. Higher efficiency of the higher rate of turbidity removal can also be attributed to the Faraday law. According to the Faraday law, $m=\frac{M I t}{z F}$ the quantity of metal ions (m) is dependent upon the intensity of the applied current (l) and electrolysis time (t). So, concentration of coagulants increases along with an increase in the above parameters.

However, in this research no significant increase was observed in turbidity changes as the $\mathrm{pH}$ value increased. The $\mathrm{Al}^{+3}$ and $\mathrm{OH}^{-}$ions produce various monomerics such as $\mathrm{Al}(\mathrm{OH})^{2+}, \mathrm{Al}(\mathrm{OH})_{2}^{+2}$ and polymerics such as $\mathrm{Al}_{6}(\mathrm{OH})_{15}^{3+}, \mathrm{Al}_{7}(\mathrm{OH})_{17}^{4+}$ and $\mathrm{Al}_{13}(\mathrm{OH})_{34}^{5+}$ when the $\mathrm{pH}$ varies between 4 to 9 in value, which eventually transform into insoluble $\mathrm{Al}(\mathrm{OH})_{3}$ flake through chemical reactions percipitation/polymerization. $\mathrm{Al}(\mathrm{OH})_{3}$ coagulums 
contain a larger surface which is suitable for the absorption of soluble organic compounds and trapping coloidal fragments. Therefore, the concentration of the coagulants such as $\mathrm{Al}(\mathrm{OH})^{2+}$ and $\mathrm{Al}(\mathrm{OH})_{3}$ are similar in this range of the $\mathrm{pH}$ value [6].

\section{Investigation of the effect of independent variables on raw sugar beet juice colour changes}

Colour is another one of the important factors in the purification of the juice. Melanins formed as the result of the enzymatic browning reactions are among the most important colour substances fromed in the syrupe by diffusion. Although these colour compounds are superficially absorbed by the calcium carbonate crystals during the later stages, the results however indicated that during electrocoagulation the colour intensifies as the voltage and time are increased (Figure 3).

Although the increase in voltage did not significantly effect the intensification of the colour, however it can be attributed to the increase in bubbles and the subsequent increase in enzymatic activity during floatation. It seems that the increase in enzymatic activity intensifies the melanin colour with the passage of time due to the openness of the reactor cell during flotation and aeration. Increase in the $\mathrm{pH}$ value, however, only slighty intensified the colour. These resuls correspond with the results of the reaserch carried out on the elimination of colour from coloured wastewater through electrocoagulation [6].
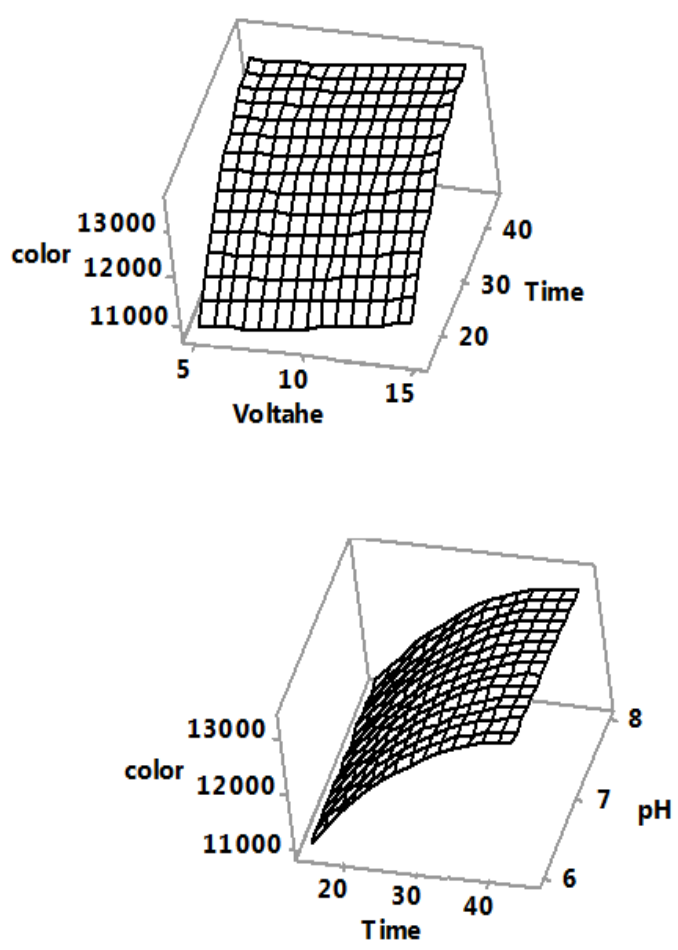
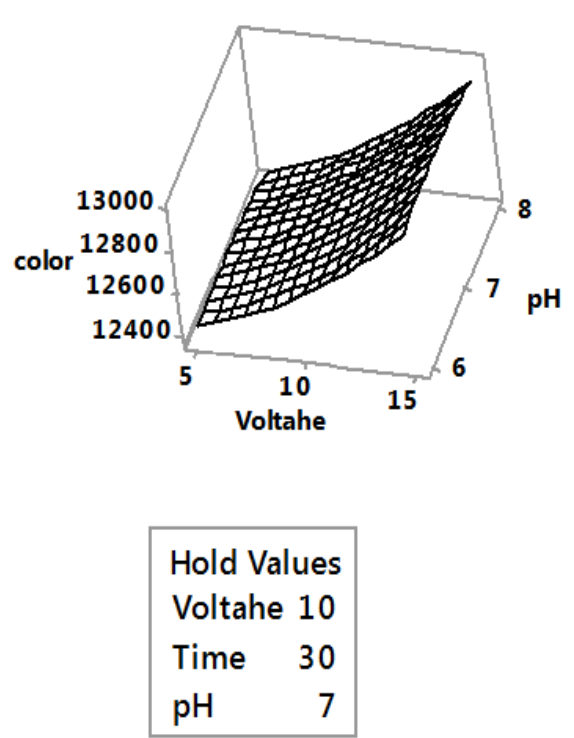

Figure 3. Effects of voltage, time and $\mathrm{pH}$ on variability of juice color 


\section{changes \\ Investigation of the effect of independent variables on raw sugar beet juice purity}

An increase in the purity level of the raw sugar beet juice during purification is indicative of desirable removal of the non-sucrose soluable and insoluable compounds. The results according to Figure 4 indicated that the increase in voltage resulted in increase in the level of purity. As explained previously, the solubility of the anodal electrodes increases as the voltage rises and subsequently a higher quantity of impurities and polutants are removed by aluminium hydroxides produced. Increase in voltage also leads to production of greater quantity of bubbles which increase contact between aluminium hydroxides with the pollutants and impurities and facilitates the floatation of more of the produced sludge and thus removal of a greater quantity of the impurities. Increase in process time also resulted in an increase in the level of purity as the an increase in reaction time results in more floating sludge is produced on the fluid surface. Increase in the $\mathrm{pH}$ value had no significant effect on the level of purity.
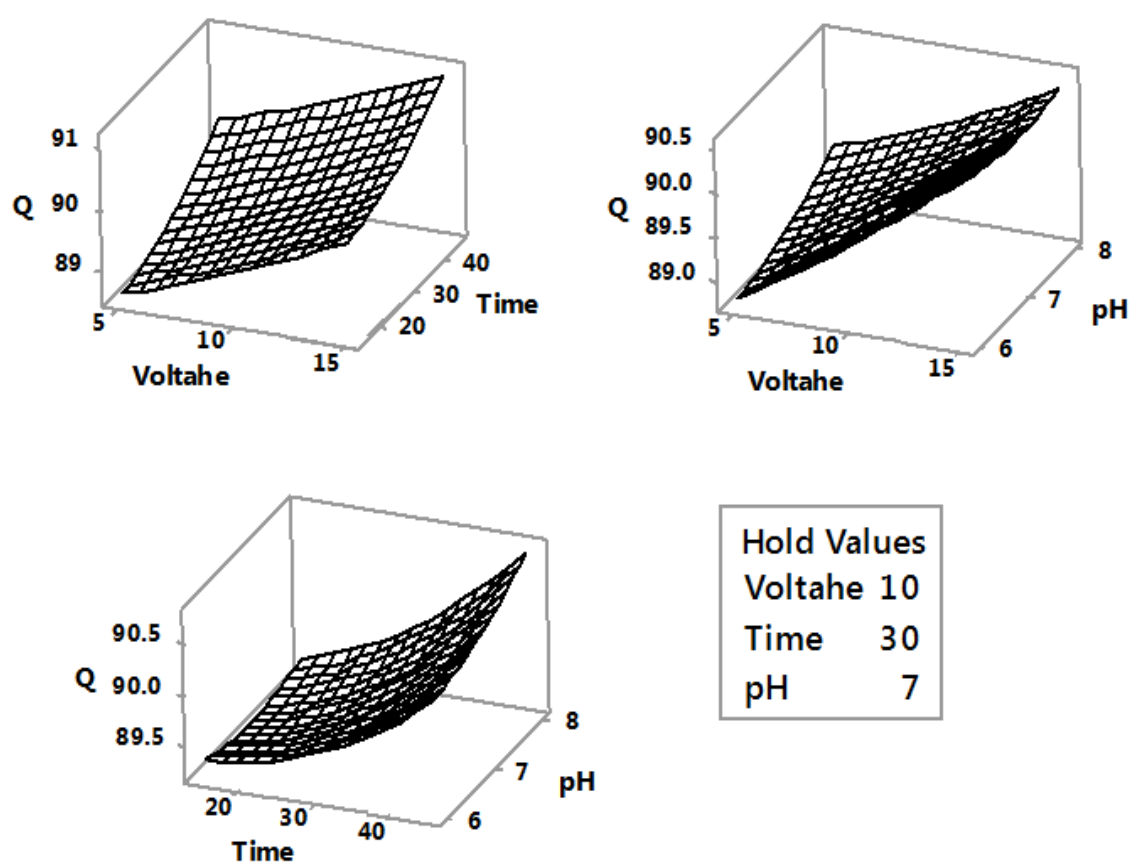

Figure 4. Effects of voltage, time and $\mathrm{pH}$ on variability of juice purity Comparison EC process with traditional refining method

For the judgment of EC process performance to refining the sugar beet juice, the properties of obtained sugar juice by EC process was compared to peroperties of thin juice from Chenaran sugar plant by traditional method. As seen in the table 3 purity reached to the purity of thin juice approximately. EC process to removal of turbidity was very succesful, too. But removal of color by this method not suitable because of flotation and Intensification of enzymatic browning. Although, it can hoped that color would removed by supplementary process as filtration. 
Table 3

Compare the properties of refined sugar beet juice by EC process with thin juice (traditional method)

\begin{tabular}{|c|c|c|c|}
\hline Properties & Raw sugar beet juice & EC process & $\begin{array}{c}\text { Traditional } \\
\text { process }\end{array}$ \\
\hline Turbidity (NTU) & 166 & 20 & 19 \\
\hline Color (ICUMSA) & 10520 & 11500 & 1400 \\
\hline Purity (\%) & 88.6 & 91 & 91.5 \\
\hline
\end{tabular}

Analysis of operational parameter and coefficient of full quadratic model

Table 4

\begin{tabular}{|c|c|c|c|c|c|c|c|c|c|c|}
\hline \multirow[b]{2}{*}{ Source } & \multirow[b]{2}{*}{ DF } & \multicolumn{3}{|c|}{ Turbidity } & \multicolumn{3}{|c|}{ Color } & \multicolumn{3}{|c|}{ Purity } \\
\hline & & $\tilde{\infty}$ & 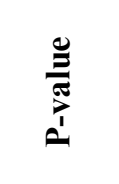 & 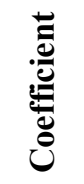 & $\mathscr{\omega}$ & 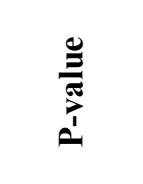 & ن & $\tilde{n}$ & 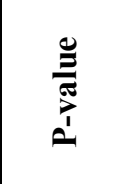 & 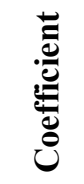 \\
\hline Model & 9 & & 74.9597 & 0.009 & & 11091621 & 0 & & \begin{tabular}{|l|}
7.08433 \\
\end{tabular} & 0.018 \\
\hline Constant & & 24.9 & & 0 & 12635.5 & & 0 & 89.600 & & 0.000 \\
\hline \multicolumn{11}{|l|}{ Linear } \\
\hline $\mathrm{V}$ & 1 & -2.408 & 46.3685 & 0.001 & 276 & 609463 & 0 & 0.700 & 3.92 & 0.002 \\
\hline $\mathrm{T}$ & 1 & -1.648 & 21.7140 & 0.003 & 1092.2 & 9543664 & 0 & 0.575 & 2.645 & 0.004 \\
\hline $\mathrm{P}$ & 1 & -0.506 & 2.5088 & 0.130 & -16.4 & 2155 & 0.461 & 0.125 & 0.125 & 0.317 \\
\hline \multicolumn{11}{|l|}{ Quadratic } \\
\hline $\mathrm{V} \cdot \mathrm{V}$ & 1 & 0.1 & 0.0369 & 0.835 & 71.4 & 18817 & 0.065 & 0.063 & 0.01442 & 0.721 \\
\hline $\mathrm{T} \cdot \mathrm{T}$ & 1 & -0.590 & 1.2853 & 0.252 & -487.8 & 878715 & 0 & 0.213 & 0.16673 & 0.255 \\
\hline $\mathrm{P} \cdot \mathrm{P}$ & 1 & -0.145 & 0.0766 & 0.763 & -29.2 & 3140 & 0.380 & 0.113 & 0.04673 & 0.527 \\
\hline \multicolumn{11}{|l|}{ Interaction } \\
\hline $\mathrm{V} \cdot \mathrm{T}$ & 1 & 0.460 & 0.8464 & 0.341 & -43.9 & 7709 & 0.192 & -0.025 & 0.00250 & 0.881 \\
\hline $\mathrm{V} \cdot \mathrm{P}$ & 1 & 0.655 & 1.7161 & 0.195 & 1.3 & 7 & 0.967 & -0.175 & 0.12250 & 0.321 \\
\hline $\mathrm{T} \cdot \mathrm{P}$ & 1 & -0.315 & 0.3969 & 0.504 & -38.3 & 5868 & 0.245 & 0.125 & 0.06250 & 0.467 \\
\hline Residual & 5 & & 11.765 & & & 16395 & & & 0.50500 & \\
\hline $\begin{array}{l}\text { Lack-of- } \\
\text { fit }\end{array}$ & 3 & & 3.8295 & $*$ & & 16395 & $*$ & & 0.50500 & $*$ \\
\hline Pure error & 2 & & 0.000 & & & 0.000 & & & 0 & \\
\hline Total & 14 & & 78.7892 & & & 11108556 & & & \begin{tabular}{|l}
7.58933 \\
\end{tabular} & \\
\hline $\mathrm{R}^{2(\%)}$ & & \multicolumn{3}{|c|}{95.14} & \multicolumn{3}{|c|}{99.85} & \multicolumn{2}{|c|}{93.35} & \\
\hline Adj-R $^{2(\%)}$ & & \multicolumn{3}{|c|}{86.32} & \multicolumn{3}{|c|}{99.57} & \multicolumn{2}{|c|}{81.37} & \\
\hline
\end{tabular}




\section{Conclusion}

The results generally indicated that electrocoagulation process has positively affected the reduction in turbidity and increase in the purity of the raw sugar beet juice during the process of purification though colour intensity was not so significantly influenced. Investigation of the independent parameters indicated that increases in the voltage and process time of coagulation significantly affected the reduction in turbidity and increase in purity such that the turbidity was reduced by $87 \%$ incomparison with the initial raw sugar beet juice while the purity increased by three units. Changes in the $\mathrm{pH}$ in the 6-8 range however, had no noticeable effect on Turbidity, colour, and purity. Although the results of this research indicated only a slight increase in the colour intensity of the raw sugar beet juice due to floatation and enzymatic browning, it is hoped that the colour produced can be removed by absorbtion on the surface of bentonit powder or active carbon by filtration. The operational parameters in this research were effective on the variations of color, turbidity and purity with appropriate $\mathrm{R}^{2}$. Analysis of operational parameters effectivness subject the full quadratic model summarized in table 4. This process can be offered as an effective method in the purification of the raw sugar beet juice in combination with other purification methods.

\section{Acknowledgements}

The authors would like to thanks Laboratory chef and univesity president of Islamic Azad University, Quchan branch for his assistance in this project.

\section{References}

1. Asgari G., Mohammadi A., Roshanaei G., Sharifi Z., Mehralipoor J., Shabanloo A., Shabanloo M. (2013), Investigation of the performance of the electrocoagulation and electrocoagulation/floatattion processes in the removal of seasonal Turbidity by using iron and aluminium electrodes, Water and Wastewater Journal, 24(2), pp. 62-69.

2. Bazrafshan E., Moein H., Kordmostafapour F., Nakhaie S. (2013), Application of Electrocoagulation Process for Dairy Wastewater Treatment, J Chem, 64013, pp. 1-8.

3. Chaturvedi S.I. (2013), Electrocoagulation:ANovel Wastewater Treatment Method. International Journal of Modern Engineering Research (IJMER), 3, pp. 93-100.

4. Chen G. (2004), Electrochemical technologies in wastewater treatment. Sep Purif Technol, 38, pp. 11-41.

5. Emamjomeh M., Sivakumar M. (2009), Review of pollutants removed by electrocoagulation and electrocoagulation/flotation processes, J Environ Manage, 90, pp. 1663-1679.

6. Ghanbari F., Mazaheri A., Mehdipoor F., Mir Shafian S., Moradi M., Sharifi Maleksari H. (2013), Investigation of the effect of the electrocoagulation on the removal of colour from coloured sewage by using aluminium/iron and aluminium/copper electrodes, Journal of Sabzevar University of Medical Sciences. 20(5), pp. 716-725.

7. Gil G.E and Wright P.H. (1994), Process for producing refined sugar from raw juices, US Patent No. 5, pp. 281, 279. 
8. Hakimzade V., Razavi S.M.A., Piroozifard M. K., Shahidi M. (2006), The potential of microfiltration and ultrafiltration process in purification of raw sugar beet juice, Desalination, 200, pp. 520-522.

9. Kobya M., Can O.T., Bayramoglu M. (2003), Treatment of textile wastewaters by electrocoagulation using iron and aluminum electrodes, J Hazard Mater, 100, pp. 163-178.

10. Yousuf A.M., Schennach R., Parga J.R., Cocke D.L. (2001), Electrocoagulation (EC)_Science and applications, J Hazard Mater, 84, pp. 29-41.

11. Parga JR., Cocke DL., Valenzuela JL., Gomes JA., Kesmez M., Irwin G., Moreno H., Weir M., (2005), Arsenic removalvia Electrocoagulation from heavy metal contaminated groundwater in La Comarca Lagunera Mexico, J Hazard Mater, 124(13), pp. 247-5.

12. Shivayogimath C.B., Jahagirdar R., (2013), Treatment Of Sugar Industry Wastewater Using Electrocoagulation Technique, Int J Res Eng Technol, 262-265.

13. The Official ICUMSA Method GS 1/2/3/9-1, (2011), The Determination of the Polarisation of Raw Sugar by Polarimetry.

14. The Official ICUMSA Method GS 2/3-18 (2013), The Determination of the Turbidity of White Sugar Solutions.

15. The Official ICUMSA Method GS 9/1/2/3-8 (2011), The determination of sugar solution color at $p H 7.0$ by MOPS buffer method.

16. Vaccari G., Tamburini E., Sgualdino G., Urbaniec K., Klemes J., (2005), Overview of the environmental problems in beet sugar processing:possible solution, $J$ Clean Prod, 13, pp. 499-507.

17. Xu L.J., Sheldon B.W., Larick D.K., Carawan R.E., (2002), Recovery and Utilization of Useful By-products from Egg Processing Wastewater by Electrocoagulation, Poult Sci, 81(6), pp. 785-79. 